\title{
PENGARUH KUALITAS PELAYANAN TERHADAP PENINGKATAN PASIEN RAWAT INAP DI RSI NASHRUL UMMAH LAMONGAN
}

\author{
*(Nurus Safa'atillah', Atik Nur Rohmah Wati² \\ Prodi Manajemen, Fakultas Ekonomi, Universitas Islam Lamongan \\ $\mathrm{Jl}$. Veteran No.53A Lamongan \\ Telp. ( 0322 ) 324706, Faks. ( 0322 ) 324706 \\ Email :jpim.unisla@gmail.com
}

\begin{abstract}
ABSTRAK
Penelitian pengaruh kualitas pelayanan pasien BPJS terhadap peningkatan pasien rawat inap BPJS di RSI Nasrul Ummah Lamongan bertujuan mengetahui kualitas pelayanan yang terdiri dari keandalan, daya tanggap, jaminan, empati, serta bukti fisik berpengaruh secara parsial maupun secara simultan.Dan variabel manakah yang berpengaruh paling dominan terhadap peningkatan pasien rawat inap BPJS di RSI Nashrul Ummah Lamongan. Dari hasil penelitian dapat ditarik kesimpulan bahwa kualitas pelayanan berpengaruh signifikan terhadap peningkatan pasien baik secara parsial maupun simultan. Secara parsial, sebaiknya variabel Responsives dan Assurance perlu dievaluasi serta lebih ditingkatkan karena tidak berpengaruh signifikan terhadap peningkatan pasien di RSI Nashrul Ummah Lamongan.
\end{abstract}

Kata Kunci: Kualitas Pelayanan (daya tanggap, jaminan, empati, serta bukti fisik),Kepuasan Konsumen

\section{PENDAHULUAN}

Kesehatan adalah salah satu faktor utama bagi setiap manusia untuk melakukan segala aktivitas sehari-hari. Selain kesehatan rohani, kesehatan jasmani juga sangat bibutuhkan oleh manusia dalam mendukung pelaksanaan segala kegiatan dan aktivitas

Pelayanan yang baik akan mempengaruhi kepuasan dari pelanggan atau pengguna jasa itu sendiri. Kepuasan Pelanggan adalah respon emosional terhadap pengalaman - pengalaman yang berkaitan dengan produk atau jasa yang dibeli (Westrbrook dan Reilly dalam buku Tjiptono, 2014:353).

BPJS sebagai salah satu perusahaan milik negara yang bergerak di bidang penyelenggaraan asuransi secara nasional, yang dalam pelaksanaannya mengacu pada UU No. 40 Tahun 2004 dan UU Nomor 24 tahun 2011. Sesuai UU Nomor 40 tahun 2004 tentang Sistem Jaminan Sosial Nasional, BPJS merupakan badan hukum nirlaba.

Pada saat ini masyarakat pengguna jasa rumah sakit tidak hanya mementingkan hasil akhir saja yang berupa kesembuhan dirinya atau kepuasan keluarga semata, tetapi mereka sudah menilai apa yang mereka lihat dan rasakan saat dirawat inap di rumah sakit. Mengamati permasalahan tersebut, maka dalam memenuhi harapan pasien pihak manajemen rumah sakit dapat bertindak sesuai dengan kemauannya sendiri dalam memutuskan semua 
kebijakan operasional, tetapi harus mampu mewujudkan pelayanan, kepercayaan serta komitmen yang terbaik pada pasiennya jika tidak ingin ditinggalkan oleh masyarakat sebagai pelanggan utamanya di masa yang akan datang.

\section{TINJAUAN PUSTAKA \\ Pengertian Kualitas Pelayanan}

Menurut Tjiptono (2014:266)

Kualitas produk (baik barang atau jasa) berkontribusi besar pada kepuasan pelanggan, retensi pelanggan, pembelian ualang, loyalitas pelanggan, pangsa pasar dan profitabilitas.

Menurut Wyckof (dalam Tjiptono 2014:268) kualitas jasa merupakan tingkat keunggulan (excellence) yang diharapkan dan pengendalian atas keunggulan tersebut untuk memenuhi keinginan pelanggan.

Sehingga definisi kualitas pelayanan dapat diartikan sebagai upaya pemenuhan kebutuhan dan keinginan konsumen. Kualitas pelayanan (service quality) dapat diketahui dengan cara atau perolehan dengan pelayanan yang sesungguhnya mereka harapkan.

\section{Dimensi Kualitas Pelayanan}

Dari artikel Parasuraman, et al. (dalam Tjiptono, 2014:282) bahwa terdapat 10 (sepuluh) dimensi pokok kualitas pelayanan sebagai berikut:

1. Bukti fisik (Tangibles), meliputi penampilan fasilitas fisik, peralatan, personil, dan bahan-bahan komunikasi perusahaan.

2. Reliability, mencangkup dua aspek utama, yaitu konsistensi kinerja (performance) dan sifat kepercayaan (dependability) yaitu kemampuan perusahaan menyampaikan layanannya secara benar sejak awal, memenuhi janjinya secara akurat dan andal.

3. Responsive atau daya tanggap yaitu kesediaan dan kesiapan para karyawan untuk membantu dan melayani para pelanggan dengan segera, diantaranya ketepatan waktu layanan, kecepatan menghubungi kembali pelanggan, dan penyampaian layanan secara cepat.

4. Kompetensi, yaitu penguasaan ketrampilan dan pengetahuan yang dibutuhkan agar dapat melayani sesuai dengan kebutuhan pelanggan. Termasuk didalamnya adalah pengetahuan dan ketrampilan karyawan.

5. Kesopanan (courtesy), meliputi sikap santun, respek, atensi dan keramahan para karyawan.

6. Kredibilitas, yaitu sifat jujur dan dapat dipercaya Kredibilitas mencangkup nama perusahaan, reputasi perusahaan, karakter pribadi karyawan dan interaksi dengan pelanggan.

7. Keamanan (Security), yaitu bebas dari bahaya, resiko atau keragu-raguan termasuk di dalamnya adalah keamanan secara fisik (physical safety), keamanan financial (finalcial security), privasi dan kerahasiaan (confidentiality).

8. Akses, meliputi kemudahan untuk dihubungi atau ditemui (approachability) dan kemudahan kontak. Hal ini berarti lokasi fasilitas layanan mudah dijangkau, 
waktu mengantri atau menunggu tudak terlalu lama, saluran komunikasi mudah dihubungi.

9. Komunikasi, penyampaian artinya kepada para pelanggan dalam bahasa yang mudah dipahami, masalah yang mungkin timbul.

10. Kemampuan pelanggan, yaitu berupa memahami pelanggan dan kebutuhan spesifik mereka, memberikan perhatian individual, dan mengenal pelanggan regular.

\section{Kepuasan Konsumen}

Howard \& Sheth (dalam Tjiptono, 2014:353) mengungkapkan bahwa kepuasan pelanggan adalah situasi kognitif pembeli berkenaan dengan kesepadanan atau ketidaksepadanan antara hasil yang didapatkan dibandingkan dengan pengorbanan yang dilakukan.

Westbrook \&Reilly berpendapat bahwa kepuasan pelanggan adalah respon emosional terhadap pengalaman-pengalaman berkaitan dengan produk atau jasa tertentu yang dibeli, garansi ritel, atau bahkan pola perilaku (seperti perilaku belanja dan perilaku membeli), serta pasar secara keseluruhan.

Tse \& Wilton (dalam Tjiptono, 2014:353)mendefinisikan

kepuasan/ketidakpuasan pelanggan adalah respon pelanggan terhadap evaluasi persepsi atas ketidak sesuaian perbedaan antara harapan awal sebelum pembelian (atau standar kinerja lainnya) dan kinerja aktual produk sebagaimana dipersepsikan setelah memakai atau mengkonsumsi produk bersangkutan.

\section{Pengukuran Kepuasan Konsumen}
Menurut Tjiptono (2014:369) prinsip dasar yang melandasi pentingnya pengukuran kepuasan pelanggan adalah doing best what matter most to customers (melakukan yang terbaik aspek-aspek terpenting bagi pelanggan). Secara garis besar ada empat metode yang digunakan untuk mengukur kepuasan pelanggan yakni:
1. Sistem keluhan dan saran
2. Ghost shopping/mystery shopping yaitu memakai jasa orang-orang yang menyamar menjadi pelanggan untuk mengetahui aspek-aspek layanan dan kulitas produk.

3. Lost Customer Analysis yaitu mewawancarai pelanggan yang ntelah beralih menjadi pemasok dan melakukan perbaikan layanan.

4. Survei kepuasan pelanggan adalah metode survei melalui via post,telepon,email,website,blog maupun tatap muka langsung.

\section{BPJS (Badan Penyelenggara Jaminan Soaial) Kesehatan}

Berdasarkan Undang-undang Nomor 24 Tahun 2011, BPJS akan menggantikan sejumlah lembaga jaminan sosial yang ada di Indonesia yaitu lembaga asuransi jaminan kesehatan PT Askes Indonesia menjadi BPJS Kesehatan dan lembaga jaminan sosial ketenaga kerjaan PT Jamsostek menjadi BPJS Ketenagakerjaan. Transformasi PT Askes dan PT Jamsostek menjadi BPJS dilakukan secara bertahap. Pada awal 2014, PT Askes akan menjadi BPJS Kesehatan, selanjutnya pada 2015 giliran PT Jamsostek menjadi BPJS Ketenagakerjaan. Lembaga ini bertanggung jawab terhadap Presiden. BPJS berkantor pusat di Jakarta, dan bisa memiliki kantor perwakilan di 
tingkat provinsi serta kantor cabang di tingkat kabupaten kota.

Dasar hukum BPJS Kesehatan :

1. Undang-Undang Dasar 1945

2. Undang-Undang Republik Indonesia Nomor 40 Tahun 2004 tentang Sistem Jaminan Nasional

3. Undang- Undang Republik Indonesia Nomor 24 Tahun 2011 Tentang Badan Penyelenggara Jaminan Sosial

Fungsi BPJS ialah sebagai berikut :

UU BPJS menentukan bahwa BPJS Kesehatan

berfungsi menyelenggarakan program jaminan kesehatan. Jaminan Kesehatan menurut UU SJSN diselenggarakan secara nasional berdasarkan prinsip asuransi sosial dan prinsip ekuitas, dengan tujuan menjamin agar peserta memperoleh manfaat pemeliharaan kesehatan dan perlindungan dalam memenuhi kebutuhan dasar kesehatan. BPJS Ketenagakerjaan menurut UU BPJS berfungsi menyelenggarakan 4 program, yaitu program jaminan kecelakaan kerja, jaminan hari tua, jaminan pensiun, dan jaminan kematian.

\section{METODELOGI PENELITIAN}

Hipotesa sementara peneliti menduga RSI Nashrul Ummah Lamongan menerapkan 5 kualitas pelayanan yang terdiri dari reability, responsivess, assurance, emphaty, dan tangible agar dapat memuaskan pasiennya terutama yang menggunakan kartu BPJS. Sehingga pasien yang memilih untuk dirawat di RSI Nashrul Ummah Lamongan dapat meningkat. Hal tersebut dapat dibuktikan dengan cara peneliti melakukan uji penelitian yang terdiri dari uji validitas, uji reabilitas, analisa regresi berganda, uji asumsi klasik, analisa korelasi berganda, koefifien determinasi $r$, uji t dan uji F.

Jurnal Penelitian Ilmu Manajemen

\section{HASIL PENELITIAN DAN PEMBAHASAN \\ Uji Validitas}

Dari hasil pengujian validitas dapat dilihat dan diinterpretasikan bahwa dari keseluruhan item variabel penelitian, mempunyai $r_{\text {hitung }}>r_{\text {tabel }}$ yaitu pada taraf signifikan 95\% $(a=0,05)$ dan $\mathrm{df}=\mathrm{n}-2=98$, dapat diketahui bahwa $\mathrm{r}_{\text {tabel }}=0,196$ dan $\mathrm{r}_{\text {hitung }}$ sebagai berikut : $\mathrm{X}_{1} 1=0,809$, $\mathrm{X}_{12}=0,760, \mathrm{X}_{1} 3=0,805, \quad \mathrm{X}_{2} 1=$ $0,875, X_{2} 2=0,838, X_{2} 3=0,837, X_{3} 1$ $=0,824, X_{3} 2=0,647, X_{3} 3=0,824$, $\mathrm{X}_{4} 1=0,838, \mathrm{X}_{4} 2=0,870, \mathrm{X}_{4} 3=$ $0,892, X_{5} 1=0,797, X_{5} 2=0,827, X_{5} 3$ $=0,794, \mathrm{Y}_{1}=0,716, \mathrm{Y}_{2}=0,812, \mathrm{Y}_{3}=$ 0,715. Maka dapat diketahui $\mathrm{r}_{\text {hitung }}$ tiap-tiap item $>0,196$. Sehingga dapat dikatakan bahwa seluruh item variabel penelitian adalah valid untuk digunakan sebagai instrumen dalam penelitian atau pertanyaan-pertanyaan yang diajukan untuk mengukur variabel yang diteliti.

Uji Realibilitas

Dari hasil uji menunjukkan bahwa nilai VIF semua variabel bebas dalam penelitian ini lebih kecil dari 10 sedangkan nilai toleransi semua variabel bebas lebh dari 0,1 atau $10 \%$ yang berarti tidak terjadi korelasi antar variabel bebas, dengan demikian dapat disimpulkan bahwa tidak terdapat gejala mutikolinearitas antar variabel bebas dalam model regresi.

\section{Uji Heteroskedastisitas}

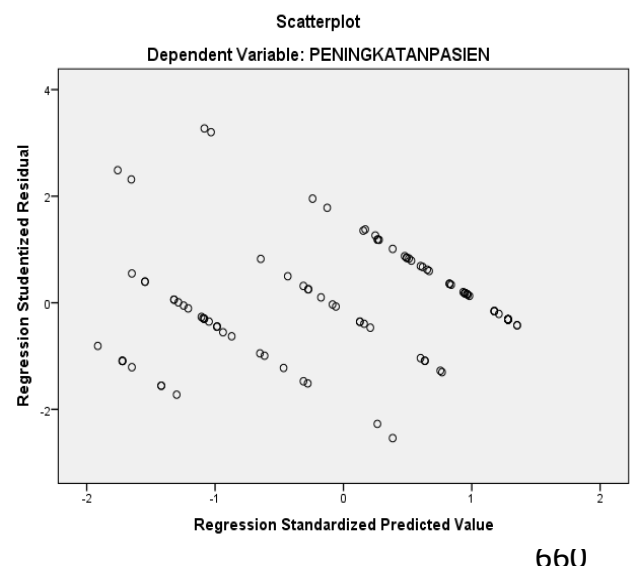


Dari gambar diatas menunjukkan bahwa titik-titik yang dihasilkan tidak membentuk suatu polatertentu dan titik-titik tersebut menyebar diatas dan dibawah angka 0 pada sumbu Y. Hal ini dapat disimpulkan bahwa model regresi linear berganda dalam penelitian ini tidak terjadi heteroskedastisitas.

\section{Uji Autokorelasi}

Tabel 1. Uji Autokorelasi

\begin{tabular}{|l|r|}
\hline Model & Durbin-Watson \\
\hline 1 & 1,981 \\
\hline
\end{tabular}

Dari tabel tersebut didapatkan nilai Durbin-Watson (DW hitung) sebesar 1,981, sedangkan dari tabel DW dengan signifikansi 0,05 dan $\mathrm{n}=$ 100 serta $\mathrm{k}=6$ diperoleh nilai $\mathrm{dL}$ sebesar 1,549 dan dU sebesar 1,803. Karena nilai DW sebesar $(1,981)$ berada pada daerah diantara dU $(1,803)$ dan 4-dU $(2,197)$ atau dU $<$ DW $<4-d U$ $(1,803<1,981<2,197)$, maka menerima $\mathrm{H}_{0}$ dan menolak $\mathrm{H}_{0}$, sehingga dapat disimpulkan bahwa tidak terjadi autokorelasi pada data dalam pengamatan.

\section{Analisis Regresi Berganda}

Berdasarkan hasil perhitungan regresi pada tabel tersebut didapatkan suatu persamaan regresi sebagai berikut :

Tabel 2. Hasil Regresi Berganda

\begin{tabular}{|l|r|r|}
\hline \multirow{2}{*}{ Model } & \multicolumn{2}{|c|}{$\begin{array}{c}\text { Unstandardized } \\
\text { Coefficients }\end{array}$} \\
\cline { 2 - 3 } & \multicolumn{1}{|c|}{ B } & \multicolumn{1}{c|}{ Std. Error } \\
\hline (Constant) & 1,279 & 1,040 \\
REABILITY &, 283 &, 059 \\
\hline RESPONSIVES &,- 030 &, 057 \\
ASSURANCE &, 091 &, 067 \\
EMPHATY &, 297 &, 062 \\
\hline TANGIBLE &, 286 &, 061 \\
\hline \\
Y $=1,279+0,283 \mathrm{X}_{1-}-0,030 \mathrm{X}_{2}+$ \\
$0,091 \mathrm{X} 3+0,297 \mathrm{X} 4+0,286 \mathrm{X}^{2}$
\end{tabular}

Dimana :

$\mathrm{Y}=$ Peningkatan Pasien

$\mathrm{X}_{1}=$ Reability

$\mathrm{X}_{2}=$ Responsives

$\mathrm{X}_{3}=$ Assurance

$\mathrm{X}_{4}=$ Emphaty

$\mathrm{X}_{5}=$ Tangible 


\section{Analisis Korelasi Berganda}

Koefisien korelasi antara variabel bebas (Reability, Responsives, Assurance, Emphaty dan Tangible) dan variabel terikat (Peningkatan Pasien) adalah sebesar 0,829. Sesuai dengan pedoman pemberian interpretasi koefisen korelasi maka dapat disimpulkan bahwa hubungan antara dua variabel adalah kuat dan bersifat positif.

\subsection{Uji Koefisien Determinasi $\left(R^{2}\right)$}

Tabel 3. Hasil Uji Koefisien Determinasi

Model Summary ${ }^{b}$

\begin{tabular}{|c|c|r|r|r|}
\hline $\begin{array}{c}\text { Mod } \\
\text { el }\end{array}$ & $\mathbf{R}$ & $\begin{array}{c}\mathbf{R} \\
\text { Square }\end{array}$ & $\begin{array}{c}\text { Adjust } \\
\text { ed R } \\
\text { Square }\end{array}$ & $\begin{array}{c}\text { Std. } \\
\text { Error of } \\
\text { the } \\
\text { Estimate }\end{array}$ \\
\hline 1 & $\begin{array}{r}, 829 \\
\mathrm{a}\end{array}$ &, 688 &, 671 &, 58818 \\
\hline
\end{tabular}

Dari Tabel 3 dapat dilihat bahwa perhitungan regresi dapat diketahui bahwa koefisien determinasi (adjusted $\mathrm{R}$ square) yang diperoleh sebesar 0,671, hal ini berarti bahwa 67,1\% variabel Peningkatan Pasien dapat dijelaskan oleh variabel Reability, Responsives, Assurance, Emphaty dan Tangible. Sisanya 32,9 \% variabel Peningkatan Pasien dapat dijelaskan oleh variabel atau faktor lain.

\section{Uji Parsial (Uji T)}

Tabel 4. Hasil Uji T

\begin{tabular}{|l|r|r|}
\hline \multicolumn{1}{|c|}{ Model } & \multicolumn{1}{c|}{ T } & Sig. \\
\hline (Constant) & 1,229 &, 222 \\
RELIABILITY & 4,787 &, 000 \\
\hline RESPONSIVES &,- 524 &, 601 \\
ASSURANCE & 1,356 &, 178 \\
EMPHATY & 4,796 &, 000 \\
\hline TANGIBLE & 4,707 &, 000 \\
\hline
\end{tabular}

Berdasarkan Tabel 4 dapat diketahui bahwa dimensi yang berpengaruh adalah Reliability, Emphaty dan Tangible.

\section{Uji Simultan ( Uji F )}

Tabel 5. Hasil Uji F

\begin{tabular}{|l|l|c|c|}
\hline \multicolumn{2}{|c|}{ Model } & F & Sig. \\
\hline 1 & Regression & 41,433 &, $000^{\mathrm{b}}$ \\
\hline
\end{tabular}

Berdasarkan dari hasil analisis data diperoleh $F_{\text {hitung }}$ sebesar 41,433 sedangkan $F_{\text {tabel}} 2,31$. Karena $F_{\text {hitung }}>$ $\mathrm{F}_{\text {tabel }}$ maka $\mathrm{H}_{0}$ ditolak, artinya secara bersama-sama variabel Reability, Responsives, Assurance, Emphaty dan Tangiblemempunyai pengaruh yang signifikan terhadap Peningkatan Pasien BPJS pada RSI Nashrul Ummah Lamongan

\section{KESIMPULAN DAN SARAN Kesimpulan}

Berdasarkan penelitian yang dilakukan oleh penulis dan hasil penelitian telah dibahas di Bab V mengenai Pengaruh Kualitas Pelayanan Terhadap Peningkatan Pasien Rawat Inap BPJS Di RSI Nashrul Ummah Lamongan, maka dapat ditarik beberapa kesimpulan, antara lain:

1. Dari hasil uji $t$ dapat diperoleh $\mathrm{X}_{1}$ $=\mathrm{t}_{\text {hitung }} 4,787>\mathrm{t}_{\text {tabel }}=1,985$, maka $\mathrm{H}_{0}$ ditolak dan $\mathrm{H}_{1}$ diterima. $\mathrm{X}_{2}=$ $\mathrm{t}_{\text {hitung }}-0,524<\mathrm{t}_{\text {tabel }}=1,985, \mathrm{X}_{3}=$ $\mathrm{t}_{\text {hitung }} 1,356<\mathrm{t}_{\text {tabel }}=1,985$, maka $\mathrm{H}_{0}$ ditolak dan $\mathrm{H}_{1}$ ditolak. $\mathrm{X}_{4}=$ $\mathrm{t}_{\text {hitung }} 4,796>\mathrm{t}_{\text {tabel }}=1,985, \mathrm{X}_{5}=$ $\mathrm{t}_{\text {hitung }} 4,707>\mathrm{t}_{\text {tabel }}=1,985{\text { maka } \mathrm{H}_{0}}$ ditolak dan $\mathrm{H}_{1}$ diterima, yang artinya bahwa variabel Responsives $\left(\mathrm{X}_{2}\right)$, Assurance $\left(\mathrm{X}_{3}\right)$ tidak ada pengaruh yang signifikan secara parsial terhadap Peningkatan Pasien (Y). Sedangkan variabel Reability $\left(\mathrm{X}_{1}\right)$, Emphaty $\left(\mathrm{X}_{4}\right)$, Tangible $\left(\mathrm{X}_{5}\right)$ ada pengaruh yang siknifikan secara parsial terhadap Peningkatan 
Pasien (Y) pada RSI Nashrul Ummah Lamongan.

2. Berdasarkan dari hasil analisis data diperoleh $F_{\text {hitung }}$ sebesar 41,433 sedangkan $F_{\text {tabel }}$ 2,31. Karena $\mathrm{F}_{\text {hitung }}>\mathrm{F}_{\text {tabel }}$ maka $\mathrm{H}_{0}$ ditolak, artinya secara bersama-sama variabel Reability, Responsives, Assurance, Emphaty dan Tangible mempunyai pengaruh yang signifikan terhadap Peningkatan Pasien BPJS pada RSI Nashrul Ummah Lamongan.

3. Dari hasil regresi berganda didapatkan hasil sebagai berikut :

$\mathrm{Y}=1,279+0,283 \mathrm{X}_{1}-0,030 \mathrm{X}_{2}+$ $0,091 X_{3}+0,297 X_{4}+0,286 X_{5}$

Dengan demikian dapat ditarik kesimpulan bahwa variabel yang paling dominan mempengaruhi Peningkatan Pasien BPJS di RSI Nashrul Ummah Lamongan yang paling dominan adalah variabel Emphaty $\left(\mathrm{X}_{4}\right)$ sebesar 0,297 dengan koefisien beta sebesar 0,377 .

\section{Saran}

Berdasarkan hasil penelitian dan hasil kesimpulan yang telah diambil, maka saran-saran yang dapat penulis ajukan yang berkaitan dengan Pengaruh Peningkatan Pasien BPJS di RSI Nashrul Ummah Lamongan adalah sebagai berikut :

1. Rumah Sakit Islam Nashrul Ummah Lamongan sebaiknya terus meningkatkan mutu dari kualitas pelayanan, karena dari hasil penelitian terbukti bahwa kualitas pelayanan dapat berpengaruh secara simultan terhadap kepuasan pasien yang nantinya akan mempengaruhi jumlah peningkatan pasien.

2. Rumah Sakit Islam Nashrul Ummah Lamongan sebaiknya memperbaiki dan mengevaluasi variabel responsives dan assurance dari kualitas pelayanan.
Karena dilihat dari penelitian ini terbukti secara parsial dengan melakukan uji t bahwa variabel responsives dan assurance tidak berpengaruh signifikan terhadap kepuasan pasien BPJS yang nantinya akan berpengaruh pada paningkatan jumlah pasien BPJS. Dengan adanya perbaikan dan evaluasi terhadap kedua variabel tersebut, diharapkan dimasa yang akan dating hasil yang diperoleh bias lebih baik.

\section{DAFTAR PUSTAKA}

Munif Efendi. 2015. Pengaruh Kualitas Pelayanan Terhadap Kepuasan Pasien Pada Klinik Medika Islam Kranji Paciran Lamongan. Lamongan: Universitas Islam Lamongan.

Sri Fitriyani. 2014. Pengaruh Kualitas Pelayanan Terhadap Loyalitas Melalui Kepuasan Pasienpengguna Bpjs Di Rawat Inap Rsud Dr. Moewardi. Surakarta: Universitas Muhammadiyah Surakarta.

Sugiyono. 2014 Metode Penelitian Kuantitatif Kualitatif dan $R \& B$. Bandung: Alfabeta. 2015. Statistik untuk Penelitian. Bandung: Alfabeta.

Sunyoto. 2013. Manajemen Pemasaran. Cetakan Pertama. CAPS. Yogyakarta

Tjiptono F. 2015. Pemasaran Jasa (prinsip, penerapan, penelitian). Yogyakarta: ANDI.

Totok Supriyanto. 2013. Pengaruh Kualitas Pelayanan Medis Terhadap Tingkat Kepuasan Pasien Di Rsi Nashrul Ummah Lamongan. Lamongan: Universitas Islam Lamongan. 